\title{
A ESCOLARIZAÇÃO MÉDIA DA CLASSE TRABALHADORA NO BRASIL: desafios contemporâneos e suas raízes históricas' ${ }^{1}$
}

Valci Melo²

\begin{abstract}
Resumo
O presente estudo analisa os principais avanços e desafios que afetam o Ensino Médio no Brasil, investigando suas configurações atuais e suas raízes históricas. Para tal, além de uma pesquisa bibliográfica e documental, recorre-se às estatísticas educacionais oficiais e a um exame minucioso do mais recente dispositivo legal dedicado à intervenção na etapa educacional em tela: a Lei $n$. 13.415, de 16 de fevereiro de 2017, oriunda da Medida Provisória 746, de 22 de setembro de 2016. A investigação se deu à luz do materialismo histórico-dialético, partindo diretamente das contribuições de Marx e Engels e dialogando com outros autores que, ligados ou não a esta perspectiva teórico-metodológica, ajudam a entender a escolarização da classe trabalhadora. Ao longo do estudo, demonstrase que, apesar dos avanços obtidos na última década, estes são insuficientes para enfrentar de forma adequada os desafios históricos que ainda recaem sobre o Ensino Médio. Por fim, conclui-se que a Lei n. 13.415/2017 representa um enorme retrocesso para a referida etapa educacional, sobretudo, para a educação dos filhos da classe trabalhadora.
\end{abstract}

Palavras-chave: Ensino Médio. Avanços e desafios. Lei n. 13.415/2017.

\section{Abstract}

This study examines the main advances and challenges that affect the high school in Brazil, investigating their current design and their historical roots. To this end, besides to a bibliographical and documentary research, It was made use the official education statistics and a detailed examination of the most recent legal apparatus dedicated to intervention in the educational modality in analysis: Law $\mathrm{n}$. 13.415, dated February 16, 2017, arising from Provisional Measure 746 of September 22, 2016. The research occurred in the light of historical-dialectical materialism, starting directly from the contributions of Marx and Engels and dialoguing with others thinkers who, associated or not linked to this theoreticalmethodological perspective, help to understand the schooling of the working class. Throughout the study It is showed that, despite of advances during the past decade, these are insufficient to address adequately the historical challenges that still to affect the high school. Finally, it is concluded that the Law n. 13.415/2017 represent a major regression for that educational stage, especially for the education of students of the working class.

Keywords: High school. Progress and challenges. Law n. 13.415/2017.

\footnotetext{
${ }^{1}$ DOI: https://doi.org/10.22409/tn.15i26.p9629

${ }^{2}$ Graduado em Pedagogia pela Universidade Estadual de Alagoas (UNEAL, 2011) e em Ciências Sociais pela Universidade Federal de Alagoas (UFAL, 2017). Mestre (2016) e doutorando em Educação pela Universidade Federal de Alagoas e professor de Ensino Fundamental na rede pública municipal de São José da Tapera, Sertão Alagoano.
}

TrabalhoNecessario - www.uff.br/trabalhonecessario; Ano 15, №26/2017 


\section{Introdução}

Embora o consenso se constitua em um feito quase impossível no âmbito das ciências humanas e sociais, tal façanha parece realizável quando o assunto é a consideração do Ensino Médio como a etapa mais problemática da Educação Básica no Brasil.

No entanto, grande parte dos desafios que assolam o Ensino Médio não é novidade na historia educacional brasileira, conforme apontam vários estudos que trataram da problemática em tela (Cury, 1998; Kuenzer, 2000; Abreu, 2005; Zibas, 2005; Krawczyk; 2009; Gomes et al., 2011).

De acordo com esses autores, entre os problemas educacionais que vêm, desde longa data, caracterizando o Ensino Médio, destaca-se a acirrada dualidade entre formação geral (Ensino Médio propedêutico e, portanto, voltado à formação geral e à continuidade dos estudos em nível superior) e preparação imediata para o trabalho (ensino profissionalizante e, neste caso, com caráter terminativo).

Ao apontarem essa dualidade, os estudos demonstram que a primeira categoria esteve, majoritariamente, apenas ao alcance dos filhos da classe dirigente, ao passo que restou, quase sempre, aos filhos dos trabalhadores, quando muito, uma escolarização diretamente voltada à instrução profissional para a venda da força de trabalho.

Essa separação sócio-histórica entre a educação oferecida aos homens das palavras e aquela disponível aos homens das ações, como nos lembra Manacorda (1992), é uma constante na história da humanidade, desde a Antiguidade. Seu alicerce, como nos ensinaram Marx e Engels (1998), é a divisão da sociedade em classes sociais com interesses antagônicos e em permanente luta, ocasionada pela apropriação privada dos meios de produção material da vida social por apenas uma dessas classes.

A educação ${ }^{2}$, neste cenário, se constitui em um dos espaços privilegiados de disputa societária, na medida em que é por meio dela que as classes sociais transmitem não apenas seus conhecimentos, técnicas e habilidades, mas também, seus valores e seus projetos de sociedade.

\footnotetext{
${ }^{2}$ Referimo-nos à educação aqui em sentido amplo, englobando o processo de aprendizagem em geral, quer este se dê de forma assistemática (educação informal), de modo planejado, mas não escolar (educação não formal) ou de maneira escolarizada (educação formal) (Libâneo, 2007).
}

TrabalhoNecessario - www.uff.br/trabalhonecessario; Ano 15, №26/2017 
No caso da escolarização como direito social, embora represente uma conquista importante dos trabalhadores na disputa pelo acesso ao patrimônio cultural historicamente acumulado, não dispõe ela, na sociedade de classes, de condições objetivas para ser, efetivamente, universal e democrática. Isto porque, conforme problematiza Marx (2012, p. 45, grifos do autor), em sua Crítica do Programa de Gotha3: "Educação popular igual? O que se entende por essas palavras? Crê-se que na sociedade atual (e apenas ela está em questão aqui) a educação possa ser igual para todas as classes?".

Respondendo negativamente ao seu questionamento, dirá o autor, mais adiante:

[...] Uma coisa é estabelecer, por uma lei geral, os recursos das escolas públicas, a qualificação do pessoal docente, os currículos etc. e, como ocorre nos Estados Unidos, controlar a execução dessas prescrições legais por meio de inspetores estatais, outra muito diferente é conferir ao Estado o papel de educador do povo! (Marx, 2012, p. 45-46).

Como se vê, Marx não ignora a necessidade e a possibilidade de se garantir, por meio do Estado, condições objetivas para a existência de uma escola pública, gratuita, laica e de qualidade socialmente referenciada. Pelo contrário, desde o Manifesto Comunista que a "educação pública e gratuita a todas as crianças" (Marx; Engels, 1998, p. 58) já figurava como uma das medidas a serem postas em prática para melhorar a qualidade de vida da classe trabalhadora.

No entanto, Marx tinha consciência de que o antagonismo de classes não poderia ser superado no âmbito de uma política educacional, e sim, através da coletivização dos meios de produção. Por isso, ele critica a ingenuidade de se esperar que o Estado possa assumir a liderança de um processo educativo libertador e igualitário no interior de uma sociedade baseada na exploração e na desigualdade.

Em oposição à proposta liberal de uma educação supostamente igual para todos no seio de uma sociedade desigual, sugere Marx (2012, p. 45): "o parágrafo

\footnotetext{
${ }^{3}$ Esta obra foi escrita por Marx, em 1875, em forma de comentário ao programa de unificação de dois partidos operários alemães, realizada na cidade de Gotha, no mesmo ano. Os partidos que se fundiram foram: "[...] a Associação Geral dos Trabalhadores Alemães (na sigla alemã, ADAV), fundada em 1863, em Leipzig, por Ferdinand Lassalle [...], e o Partido Social-Democrata dos Trabalhadores (SDAP), fundado em 1869, em Eisenach, por Wilhelm Liebknecht, Wilhelm Bracke e August Bebel, dirigentes socialistas próximos de Marx" (Löwy, 2012, p. 13).
} 
sobre as escolas devia ao menos ter exigido escolas técnicas (teóricas e práticas) combinadas com a escola pública" (Marx, 2012, p. 45).

Vejamos que Marx procura enfrentar o problema da unilateralidade educacional, considerando as condições sócio-históricas, e não, de forma voluntarista e extremista. Ou seja, ele não entra na falácia liberal de ignorar a existência de classes sociais e requerer para todas as pessoas um processo educativo que as prepare, ou somente para o exercício das faculdades teóricoespirituais, ou apenas para o exercício das tarefas prático-manuais. Pelo contrário, o que propõe Marx é que a escolarização dos filhos da classe trabalhadora, que tem interesses, valores e necessidades diferentes daquela oferecida aos filhos da classe dominante, se dê no horizonte da omnilateralidade, da politecnia, do domínio das letras, das ciências, das artes e da técnica.

Vejamos que as reflexões educacionais de Marx são coerentes com a sua teoria social que vê no trabalho não apenas o fundamento ontológico do ser social, mas o núcleo organizador do mundo dos homens. Isto é, na esteira do materialismo histórico-dialético, teoria social desenvolvida por Marx e Engels, é por meio do trabalho, entendido como relação entre o homem e a natureza para a satisfação de suas necessidades, que nós superamos a condição de ser animal e nos erguemos ao status de ser social. Com isso, o intercâmbio entre nós e a natureza cumpre a função, não apenas, de satisfazer as necessidades imediatas, mas também de criar novas necessidades e as condições apropriadas para a sua satisfação. Assim, o trabalho é entendido, na teoria marxiana e marxista, como o elemento criador e organizador do mundo dos homens (Marx; Engels, 2007; Marx, 2013; Engels, 1999).

Contudo, com a divisão social do trabalho (intelectual e manual), a apropriação privada dos meios fundamentais de produção material da vida social (terras, fábricas, matérias-primas, ferramentas...), a consequente fragmentação da sociedade em classes sociais e a criação do Estado como mecanismo voltado à defesa e manutenção dos interesses das classes dominantes, o trabalho deixa de cumprir a função de realizador das potencialidades humanas, de forma universal, para se constituir em instrumento de dominação de classe (Marx; Engels, 1998; 2007; Marx, 2004; 2013).

Com o surgimento da sociedade de classes, a riqueza produzida pelo trabalho não mais pertence à coletividade humana; menos ainda àqueles que a

TrabalhoNecessario - www.uff.br/trabalhonecessario; Ano 15, №26/2017 
produzem: escravos, servos ou trabalhadores assalariados. Pelo contrário, ela passa a ser apropriada pelas classes sociais dominantes (senhores de escravo, senhores feudais e burguesia) que, por terem sob o seu domínio privado os meios de produção, se dão ao luxo de viver bem sem trabalhar, em detrimento da pauperização absoluta ou relativa ${ }^{4}$ na qual se encontram as classes trabalhadoras.

Deste modo, para Marx, não se trata de reivindicar para os trabalhadores uma escolarização que ignore a reprodução material da vida social (o trabalho). Trata-se de garantir, por meio do Estado, as condições necessárias para que os filhos dos trabalhadores desenvolvam tanto as faculdades espirituais (cognitivas, estéticas, afetivas...), como também, as técnicas e habilidades corporais e laborais.

Considerando que esse debate remonta à segunda metade do século XIX, vejamos, então, como ele tem sido considerado na operacionalização da política educacional do Estado brasileiro, mais especificamente, no que tange ao ensino de nível médio, desde a segunda metade do século XX.

\section{Breves notas sobre o Ensino Médio nas Leis de Diretrizes e Bases da Educação Nacional (LDB)}

Ainda que a polarização entre formação geral e instrumentalização, como nos mostra Saviani (2008), não seja privilégio do Ensino Médio, nessa etapa educacional, ela se intensificou e vem provocando consequências sociais mais danosas.

$\mathrm{Na}$ história da educação brasileira, não somente tivemos essa dualidade como uma das principais características, como também, as formas pelas quais se buscou superá-la, quase sempre, foram extremistas.

Ressalvadas as tentativas de enfrentamento, ao longo da década de $1950^{5}$, do caráter dual e inflexível dos vários ramos de ensino médio, a equivalência

\footnotetext{
${ }^{4}$ Ver a distinção em Paulo Netto (2007, p. 143, nota de rodapé ํㅜ 23).

${ }^{5}$ Entre as iniciativas do período está a Lei oㅜ 1.076, de 31 de março de 1950. Por meio dela, a inflexibilidade e o caráter de terminalidade do ensino técnico começou a ser abalado. Ela abria a possibilidade dos estudantes desse ramo de ensino (o técnico) acessarem o segundo ciclo (clássico e científico) do então ensino secundário, desde que aprovados em exames pautados em disciplinas desse último curso. Foi, também, por essa lei que os estudantes do curso comercial ficaram autorizados a acessarem o ensino superior (caso passassem nos exames). Para um conhecimento mais detalhado desta e das outras iniciativas, conferir: Cury (1998) e Brasil (1999, p. 8-15).
}

TrabalhoNecessario - www.uff.br/trabalhonecessario; Ano 15, № 26/2017 
entre estes somente se efetivou com a aprovação da primeira Lei de Diretrizes e Bases da Educação Nacional (LDB 4.024, de 20 de dezembro de 1961). Essa lei, ao equiparar os variados ramos de ensino médio, permitindo legalmente o fluxo entre este e o ensino superior, deu um passo à frente. No entanto, como a sociedade no interior da qual a prática educativa se dá continuou divida em classes sociais com interesses antagônicos, a dualidade persistiu, pois aquilo que a justifica e fundamenta permaneceu inalterado.

Ressalte-se, também, que embora tal possibilidade tenha se dado a partir da LDB 4.024/616, esta fica subentendida, uma vez que a referida lei trata desta questão apenas no capítulo alusivo ao Ensino superior, mais especificamente na alínea "a", do artigo 69. Na ocasião, a LDB 4.024/61 destaca que o acesso ao Ensino Superior, nos cursos de graduação, estava aberto aos "candidatos que hajam concluído o ciclo colegial ou equivalente, e obtido classificação em concurso de habilitação". Isto é, como a referida Lei, ao tratar do Ensino Médio, no artigo 34, esclarece que este é composto de dois ciclos (o ginasial e o colegial), e "abrangerá, entre outros, os cursos secundários, técnicos e de formação de professores para o ensino primário e pré-primário", entende-se que os variados ramos tinham sido equiparados e formalmente davam acesso ao Ensino superior.

Na década de 1970, por sua vez, é aprovada uma nova LDB (Lei $5.692 / 71^{7}$ ). Esse acontecimento se dá em um contexto de cerceamento dos direitos políticos e das liberdades civis, embora com algumas conquistas no campo dos direitos sociais, a exemplo do que já tinha acontecido durante o Estado Novo - a Ditadura Vargas ${ }^{8}$. É também nesse período que se busca integrar a política educacional brasileira às exigências internacionais e que se

\footnotetext{
${ }^{6}$ Nessa Lei, o sistema de escolarização nacional ficou disposto da seguinte forma: educação de grau primário (educação pré-primária e ensino primário), educação de grau médio (ensino médio, ensino secundário, ensino técnico e formação do magistério para o ensino primário e médio) e educação de grau superior (BRASIL, 1961, título VI ao título IX; art. 23 ao art. 87).

7 Já a partir da LDB 5.692/71, a organização educacional passa a se dar da seguinte maneira: ensino de $1^{\circ}$ grau, ensino de $2^{\circ}$ grau, ensino supletivo e ensino superior (BRASIL, 1971, capítulo 1 ao capítulo 5 , art. $1^{\circ}$ ao art. 40 ).

${ }^{8}$ Conforme destacam Behring e Boschetti (2011) é no governo Vargas, inclusive no período do Estado Novo, que contrastam repressão e negação aos direitos políticos com conquistas significativas no âmbito da política social, entre as quais, cabe citar, a regulamentação dos direitos trabalhistas, coroada com a outorgação, em 1943, da Consolidação das Leis Trabalhistas (CLT). Já sobre o período 1964-1985, as referidas autoras apontam que, além de uma "[...] intensa institucionalização da previdência, da saúde e, com menor importância, da assistência social [...], a ditadura impulsionou uma política nacional de habitação, com a criação do Banco Nacional de Habitação (BNH)" (Behring; Boschetti, 2011, p. 137).
}

TrabalhoNecessario - www.uff.br/trabalhonecessario; Ano 15, № 26/2017 
registra o crescimento do assalariamento urbano e a intensificação da demanda popular por escolarização.

Frente a essas exigências, a LDB 5.692/71 busca inverter, ao menos teoricamente, a lógica, até então, predominante nessa etapa educacional: a dualidade com maior valorização do ramo secundário. Alicerçada na profissionalização compulsória de todas as modalidades de ensino médio, a LDB 5.692/71 acaba por comprometer tanto o caráter técnico-profissionalizante, como também a dimensão formativo-propedêutica dessa etapa educacional. Isso porque, como observa Cury (1998, p. 79-80):

Ao ignorar os condicionantes do processo produtivo e ao ignorar a própria estratificação social e sua segmentação de classe, a lei nem atendeu à sua letra, antes favorecendo mesmo seu mascaramento, e nem foi um dique à demanda por ensino superior de vez que o setor privado desse nível conheceu uma expansão jamais vista. Além disso, a lei pecava na base, por exigir, cartorialmente, o que o sistema não tinha: uma geração de docentes competentes para as novas funções e uma infraestrutura capaz de propiciar a necessária experimentação e aplicabilidade exigidas por um ensino dessa natureza.

Embora mudanças na LDB 5.692/71 tenham ocorrido ao longo das décadas de $1970-80^{9}$, somente a Constituição Federal de 1988 foi capaz de promover alterações significativas, não apenas para esta etapa de ensino, mas para a educação em geral. A partir desta Lei (a CF de 1988), a educação foi reconhecida como o primeiro dos direitos sociais, e o Estado foi desenhado na perspectiva do bem-estar social ${ }^{10}$ (Montaño, 2002). No entanto, o contexto mundial já remava fortemente na contramão desse tipo de funcionamento estatal. Essa situação, por sua vez, colocava o Brasil em uma encruzilhada, visto que situava-se entre a proposta de um Estado providência, rascunhado na CF de

\footnotetext{
${ }^{9}$ Conforme Cury (1998), além das modificações introduzidas pela Lei ํㅡ 7.044, de 18 de outubro de 1982, a qual flexibiliza a exigência de profissionalização compulsória, facultando tal escolha aos estabelecimentos de ensino, outras leis, pareceres e decretos buscaram, ao longo da década de 1970, minimizar a rigidez da LDB 5.692/71.

${ }^{10} \mathrm{O}$ Estado de bem-estar social ou Welfare State consiste em um experimento dos países capitalistas desenvolvidos, especialmente os países da Europa Ocidental e os Estados Unidos da América, em contraposição ao risco oferecido pela União Soviética no combate às desigualdades sociais, ao crescimento do sindicalismo e da oposição de esquerda e aos efeitos drásticos da desregulamentação da economia. Como resultado, têm-se, ao longo das três décadas posteriores à Segunda Guerra Mundial, um modelo societário baseado na intervenção estatal na economia, mediante o qual o fundo público financiava tanto o setor privado como também a reprodução da força de trabalho, por meio da garantia de direitos sociais como educação, saúde, previdência social e emprego (PAULO NETTO; BRAZ, 2011, p. 205-216).
}

TrabalhoNecessario - www.uff.br/trabalhonecessario; Ano 15, № 26/2017 
1988, e o Estado mínimo, como um dos pilares fundamentais do projeto societário neoliberal, imposto aos novos tempos.

Neste cenário, o Ensino Médio aparece, na CF de 1988, como uma etapa a ser progressivamente universalizada - o que representava um enorme avanço em face de todo o histórico segregacionista anterior -, mas ficava condicionado ao total atendimento do ensino fundamental (a prioridade constitucional).

Com a LDB 9.394/96, a lógica de profissionalização, predominante na LDB 5.692/71, é superada, dando-se ao agora denominado Ensino Médio, um caráter universal e uma dimensão formativa e propedêutica.

Concebendo essa modalidade da educação como última etapa da Educação Básica ${ }^{11}$, a referida Lei, inicialmente, proíbe a integração entre formação geral e formação técnico-profissional, conforme definirá o Decreto 2.208, de 17 de abril de 1997. Contudo, a partir de 2004, não somente é retomada a perspectiva da integração entre Ensino Médio e ensino técnico (Decreto $\mathrm{n}$. 5.154 , de 23 de julho de $2004^{12}$ ), como também, se desenvolverá um conjunto de políticas, no sentido de intervir junto aos desafios que persistem na etapa educativa em análise.

É, pois, para os avanços e desafios decorrentes dessas políticas em curso que se voltará a nossa análise a partir de agora. Além disso, examinaremos como a Medida Provisória 746, de 22 de setembro de 2016, convertida na Lei n. 13.415, de 16 de fevereiro de 2017, impactará nas configurações e nos destinos do Ensino Médio.

\section{Avanços e desafios do Ensino Médio no Brasil contemporâneo}

Conforme dados do Relatório Educação para Todos no Brasil: 2000-2015 (Brasil, 2014) e do Censo Escolar da Educação Básica 2013: resumo técnico (INEP, 2014a), o Ensino Médio brasileiro tem registrado, nas últimas décadas, significativas conquistas e importantes avanços, entre os quais cabe destacar:

\footnotetext{
${ }^{11}$ Nessa Lei, a educação nacional se organiza em dois níveis: Educação Básica e Educação Superior. A Educação Básica agrupa-se em três etapas: Educação Infantil, Ensino Fundamental e Ensino Médio. As etapas do Ensino Fundamental e do Ensino Médio podem organizar-se em modalidades, a saber: Educação de Jovens e Adultos - EJA; Educação Profissional e Educação Especial (BRASIL, 1996, título V, art. 21 ao art. 60).

${ }^{12}$ Para uma análise deste decreto, ver os estudos Krawczyk (2012), Bremer e Kuenzer (2012).
} 
a Garantia da universalização do Ensino Médio, mediante a aprovação da Emenda Constitucional ํㅡ 59, de 11 de novembro de 2009, que estabelece a obrigatoriedade da Educação Básica dos 4 aos 17 anos de idade, bem como, da Lei $n^{\circ}$ 12.061, de 27 de outubro de 2009, que trata especificamente destas alterações no âmbito do Ensino Médio;

b. Inserção do Ensino Médio no Fundo de Desenvolvimento e Manutenção da Educação Básica e Valorização do Magistério (FUNDEB), mediante a Lei $\mathrm{n}$. 11.494, de 20 de junho de 2007;

c. Reintegração do Ensino Médio à Educação Profissional, por meio do Decreto 5.154, de 23 de julho de 2004 e da Lei n. 11.741, de 16 de julho de 2008 (Brasil, 2008a);

d. Aprovação de novas Diretrizes Curriculares Nacionais para o Ensino Médio (DCNEM 2012), através da Resolução CNE/CEB no 02, de 30 de janeiro de 2012;

e. Aumento da frequência de pessoas pretas/pardas, indígenas, pobres e daquelas que moram na Zona Rural ao Ensino Médio (Brasil, 2014a, p.32-36);

f. Elevação da oferta e das matrículas no Ensino Médio Integrado à Educação Profissional (Brasil, 2014, p.37-38).

No entanto, conforme indicam estudos como os de Ferreira (2011), Kuenzer (2011), Gomes et al. (2011), Pinto, Amaral e Castro (2011), Machado Costa (2013), Pereira (2014) e dados dos documentos acima referidos (Brasil, 2014; INEP, 2014a), o Ensino Médio ainda é a etapa de escolaridade na qual concentram-se, desde longa data, os mais gritantes problemas educacionais brasileiros.

Para além das conquistas e avanços, que abrem diversas possibilidades no sentido de enfrentamento do que Frigotto e Ciavatta (2011, p. 620) classificam de uma etapa educacional precária "tanto na sua base material quanto pedagógica", persistem diversos desafios. Um deles, que vem se intensificando há uma 
década, como se pode ver na tabela 1, é a oscilação negativa na taxa de matrículas.

\begin{tabular}{cccc}
\multicolumn{4}{c}{ Tabela 1 - Estudantes matriculados no Ensino Médio entre 1994 e 2016 } \\
\hline \multicolumn{1}{c}{ Ano } & $\begin{array}{c}\text { Quantidade de } \\
\text { Estudantes }^{13}\end{array}$ & Ano & $\begin{array}{c}\text { Quantidade de } \\
\text { Estudantes }\end{array}$ \\
\hline $\mathbf{1 9 9 4}$ & 4.932 .552 & $\mathbf{2 0 0 5}$ & 9.031 .302 \\
$\mathbf{1 9 9 5}$ & 5.374 .831 & $\mathbf{2 0 0 6}$ & 8.906 .820 \\
$\mathbf{1 9 9 6}$ & 5.739 .077 & $\mathbf{2 0 0 7}$ & 8.369 .369 \\
$\mathbf{1 9 9 7}$ & 6.405 .057 & $\mathbf{2 0 0 8}$ & 8.366 .100 \\
$\mathbf{1 9 9 8}$ & 6.968 .531 & $\mathbf{2 0 0 9}$ & 8.337 .160 \\
$\mathbf{1 9 9 9}$ & 7.769 .199 & $\mathbf{2 0 1 0}$ & 8.357 .675 \\
$\mathbf{2 0 0 0}$ & 8.192 .948 & $\mathbf{2 0 1 2}$ & 8.376 .852 \\
$\mathbf{2 0 0 1}$ & 8.398 .008 & $\mathbf{2 0 1 3}$ & 8.312 .815 \\
$\mathbf{2 0 0 2}$ & 8.710 .584 & $\mathbf{2 0 1 4}$ & 8.301 .380 \\
\hline $\mathbf{2 0 0 3}$ & 9.072 .942 & $\mathbf{2 0 1 5}$ & 8.076 .150 \\
\hline $\mathbf{2 0 0 4}$ & 9.169 .357 & $\mathbf{2 0 1 6}$ & 8.131 .988 \\
\hline Fonte: INEP: Sinopses estatísticas da Educação Básica (INEP, 2014b).
\end{tabular}

Apesar de ser vista oficialmente como estável (INEP, 2014a, p.20), essa situação em que se encontram as matrículas do Ensino Médio contrasta, tanto com o crescimento do Ensino Fundamental que, segundo dados do Censo Escolar da Educação Básica 2013: resumo técnico (INEP, 2014a, p. 20), apresentou, entre 2007 e 2013, "crescimento de 9,4\% no número de concluintes", como também está aquém do atendimento ao universo populacional de 15 a 17 anos (faixa etária que deve atender), o qual, em 2012, era de 10.444 .705 jovens, contra pouco mais de 8 milhões de matrículas (INEP, 2014a, p. 21).

Ainda neste aspecto, é preciso considerar que, embora a taxa de escolarização do Ensino Médio tenha atingido 84,3\% em 2013 (IBGE, 2014), além de esse percentual representar um ínfimo crescimento na última década (2,5 pontos entre 2004 e 2013), esconde o fato de que, em termo de matrícula líquida, isto é, considerando-se os estudantes regularmente matriculados na etapa educacional para a qual têm idade compatível (no caso em tela, os jovens com idade entre 15 e 17 anos) este percentual cai para 55,2\%, o que mesmo representando um crescimento significativo no período analisado (11 pontos percentuais na correção do índice de distorção idade-série entre 2004-2013),

\footnotetext{
${ }^{13} \mathrm{O}$ quantitativo de alunos matriculados corresponde à soma dos estudantes do Ensino Médio Propedêutico, Ensino Médio Normal e Ensino Médio Integrado.
}

TrabalhoNecessario - www.uff.br/trabalhonecessario; Ano 15, № 26/2017 
ainda está muito longe da universalização desejada no Plano Nacional de Educação (PNE 2014-2024), que almeja atingir 85\% até o final de sua vigência.

Outro elemento que desafia a universalização ${ }^{14}$ do Ensino Médio a ir além do que Pinto, Amaral e Castro (2011, p. 663) chamam de "massificação barata" é o baixo rendimento estudantil, marcado por altas taxas de abandono e retenção.

\begin{tabular}{cccc} 
Tabela 2 - Taxa de rendimento do Ensino Médio entre 1999 e 2015 \\
\hline Ano & $\begin{array}{c}\text { Reprovação } \\
(\%)\end{array}$ & Abandono (\%) & Total (\%) \\
\hline $\mathbf{1 9 9 9}$ & 7,2 & 16,4 & $\mathbf{2 3 , 6}$ \\
\hline $\mathbf{2 0 0 1}$ & 8,0 & 15 & $\mathbf{2 3}$ \\
$\mathbf{2 0 0 2}$ & 10,0 & 14,7 & $\mathbf{2 4 , 7}$ \\
$\mathbf{2 0 0 5}$ & 11,5 & 15,3 & $\mathbf{2 6 , 8}$ \\
$\mathbf{2 0 0 7}$ & 12,7 & 13,2 & $\mathbf{2 5 , 9}$ \\
$\mathbf{2 0 0 8}$ & 12,3 & 12,8 & $\mathbf{2 5 , 1}$ \\
$\mathbf{2 0 0 9}$ & 12,6 & 11,5 & $\mathbf{2 4 , 1}$ \\
$\mathbf{2 0 1 0}$ & 12,5 & 10,3 & $\mathbf{2 2 , 8}$ \\
$\mathbf{2 0 1 2}$ & 12,2 & 9,1 & $\mathbf{2 1 , 3}$ \\
\hline $\mathbf{2 0 1 3}$ & 11,8 & 8,1 & $\mathbf{1 9 , 9}$ \\
$\mathbf{2 0 1 4}$ & 12,1 & 7,6 & $\mathbf{1 9 , 7}$ \\
$\mathbf{2 0 1 5}$ & 11,5 & 6,8 & $\mathbf{1 8 , 3}$ \\
\hline
\end{tabular}

Fonte: INEP: Indicadores Educacionais - Educação Básica.

Como é possível ver na tabela 2, apesar da soma dos dois principais fatores responsáveis pelo índice de rendimento (reprovação e abandono) vir caindo na última década, especialmente com a diminuição da taxa de abandono, ainda alcançou, em 2015, a marca de 18,3\%, o que corresponde a quase $1 / 5$ (um quinto) de insucesso escolar nesta etapa educacional.

A esfera estadual, constitucionalmente responsável pelo Ensino Médio, em 2015 respondia por 97,1\% dos estudantes matriculados na rede pública (Brasil, 2016b, p. 52). Considerando as assimetrias entre as diversas unidades da federação, tanto no que se refere às suas possibilidades materiais e pedagógicas, como também, no modo como têm lidado com as políticas educacionais, vê-se que a universalização do acesso ao Ensino Médio exige o fortalecimento da articulação e da cooperação entre os estados e a União.

\footnotetext{
${ }^{14}$ Destaque-se aqui que se trata somente da universalização do acesso, pois no interior do sistema capitalista é impossível universalizar a educação formal como um todo, uma vez que isso exigiria condições objetivas que estão para além da ordem social vigente. Sobre o assunto, ver o capítulo $3^{\circ}$ da dissertação de mestrado intitulada (Im)possibilidades e limites da universalização da educação sob o capital, (Maceno, 2005, p. 85-117).
}

TrabalhoNecessario - www.uff.br/trabalhonecessario; Ano 15, № 26/2017 
É, pois, nesse particular que se inserem as condições de formação, trabalho e carreira docente, as quais, conforme sinalizam estudos como os de Kuenzer (2011) e Machado Costa (2013), também se constituem aspectos que desafiam o Ensino Médio.

Um primeiro ponto diz respeito à formação inicial, visto que, conforme dados do Instituto Nacional de Estudos e Pesquisas Educacionais Anísio Teixeira (INEP), em 2015, somente 93,1\% dos professores que atuavam no Ensino Médio tinham formação superior, o que demonstra a existência de professores lecionando esta etapa educacional sem ter uma graduação ou até mesmo, como sugere Machado Costa (2013, p. 97), com a possibilidade de alguns deles não terem cursado, nem ao menos, o próprio Ensino Médio. Esta situação, por sua vez, se agrava quando constatamos que, segundo dados do Censo da Educação Básica $2015^{15}$, no referido ano, dos professores com educação superior atuando no Ensino Médio, somente 52,6\% lecionavam disciplinas para as quais têm formação em licenciatura e/ou bacharelado com complementação pedagógica.

Já sobre as condições em que se dá a atuação destes trabalhadores em educação, os dados são abundantes em mostrar um intenso e contínuo processo de precarização, seja no que tange à quantidade de estudantes que atendem, na medida em que, conforme dados do INEP ${ }^{16}$, o Ensino Médio registra a maior média de estudantes por sala da Educação Básica (30,2 estudantes); seja na extensa jornada de trabalho, uma vez que parte considerável destes trabalhadores acumula carga horária, muitas delas em escolas diferentes; seja na desvalorização social e salarial, visto que, apesar da aprovação da Lei № 11.738, de 16 de julho de 2008 (Brasil, 2008b), que estabelece diretrizes para um piso nacional para os professores da Educação Básica, a remuneração paga aos docentes e a consideração da jornada com hora-atividade varia, consideravelmente, de acordo com as unidades da federação. Segundo levantamento da Confederação Nacional dos Trabalhadores em Educação (CNTE, 2014), em 2013 a maioria dos estados brasileiros não cumpria a Lei do Piso em sua integralidade (remuneração mínima mais destinação de $1 / 3$ da

\footnotetext{
${ }^{15}$ Disponível em: http://portal.inep.gov.br/indicadores-educacionais. Acesso em: 08 out. 2016.

${ }^{16}$ Indicadores Educacionais da Educação Básica/Média de alunos por turma no Brasil em 2015 (INEP, 2015).
}

TrabalhoNecessario - www.uff.br/trabalhonecessario; Ano 15, № 26/2017 
jornada de trabalho para hora-atividade) e alguns deles chegavam a não cumprir nenhum dos requisitos exigidos pela Lei.

A estes desafios históricos, soma-se, entre outros que poderiam ser aqui listados, o fato de que é nessa etapa da Educação Básica que a relação entre educação e trabalho se torna mais direta e conflituosa, seja porque parte considerável dos estudantes precisa, desde já, assumir a dupla condição de estudante e trabalhador (Ferreira, 2011), seja porque a equação escolaridade mercado de trabalho - ascensão social começa a ser percebida pelos estudantes como uma meia verdade ou uma promessa cada vez mais distante.

Um indicador neste sentido é a elevada quantidade de estudantes que frequenta o Ensino Médio no período noturno, o qual, mesmo em decréscimo, ainda correspondeu, em 2014, a 25,91\% da matrícula desta etapa educacional. Em 2009, o período noturno respondia por 37\% das matrículas do Ensino Médio. Ou seja, diante da necessidade de garantir, desde muito cedo, a própria reprodução material, parte considerável dos estudantes tem como alternativa ou o Ensino Médio noturno (quando este possibilita tal conciliação), ou o abandono escolar, como atestam os índices já indicados neste trabalho.

Diante desse cenário, não é estranho que essa etapa educacional tenha registrado desempenho aquém das metas oficialmente postas, a exemplo do Índice de Desenvolvimento da Educação Básica (IDEB) que apresenta, conforme se pode ver na tabela 3, uma estagnação desde o ano de 2011, inclusive com piora na nota obtida pelas instituições privadas.

Tabela 3 - Resultados e metas do Ensino Médio no IDEB de 2005 a 2015

\begin{tabular}{llllllllllll}
\hline & \multicolumn{1}{c}{ IDEB Observado } & \multicolumn{5}{c}{ Metas } \\
\cline { 2 - 13 } & $\mathbf{2 0 0 5}$ & $\mathbf{2 0 0 7}$ & $\mathbf{2 0 0 9}$ & $\mathbf{2 0 1 1}$ & $\mathbf{2 0 1 3}$ & $\mathbf{2 0 1 5}$ & $\mathbf{2 0 0 7}$ & $\mathbf{2 0 0 9}$ & $\mathbf{2 0 1 1}$ & $\mathbf{2 0 1 3}$ & $\mathbf{2 0 1 5}$ \\
Total & 3.4 & 3.5 & 3.6 & 3.7 & 3.7 & 3.7 & 3.4 & 3.5 & 3.7 & 3.9 & 4.3 \\
Dependência Administrativa & & & & & & & & \\
Estadual & 3.0 & 3.2 & 3.4 & 3.4 & 3.4 & 3.5 & 3.1 & 3.2 & 3.3 & 3.6 & 3.9 \\
Privada & 5.6 & 5.6 & 5.6 & 5.7 & 5.4 & 5.3 & 5.6 & 5.7 & 5.8 & 6.0 & 6.3 \\
Pública & 3.1 & 3.2 & 3.4 & 3.4 & 3.4 & 3.5 & 3.1 & 3.2 & 3.4 & 3.6 & 4.0 \\
\hline
\end{tabular}

Fonte: Instituto Nacional de Estudos e Pesquisas Educacionais Anísio Teixeira - INEP17.

Claro que se poderia problematizar aqui, tanto a metodologia utilizada pelo MEC, através do INEP, para medir a qualidade do serviço educacional prestado à população brasileira, como também, o nível de confiança desses resultados,

17 Disponível em: http://ideb.inep.gov.br/resultado/resultado/resultadoBrasil.seam?cid=382278.
Acesso em: 08 out. 2016 .

TrabalhoNecessario - www.uff.br/trabalhonecessario; Ano 15, № 26/2017 
considerando-se o que aconteceu, em outubro de 2016, com a divulgação dos resultados do Exame Nacional do Ensino Médio - ENEM de 2015. Conforme noticiou a imprensa ${ }^{18} \mathrm{e}$ admitiu o próprio INEP, em sua página na internet ${ }^{19}$, houve a desconsideração de $96 \%$ dos institutos federais (que são escolas públicas de Educação Básica) na divulgação da nota por escola - equívoco bastante tendencioso, em tempos de desqualificação do serviço público como estratégia de justificação das políticas de privatização.

No entanto, o que nos interessa aqui é o fato de que, duas semanas depois que tornou público o resultado do IDEB 2015, o Poder Executivo Federal, sob a alegação de que era urgente intervir no Ensino Médio brasileiro, publicou uma Medida Provisória, reformando essa etapa educacional. Trata-se da MP 746, de 22 de setembro de 2016, posteriormente aprovada como Lei n. 13.415, de 16 de fevereiro de 2017, a qual se propõe a fomentar a implementação de escolas de Ensino Médio de Tempo Integral e modifica a Lei de Diretrizes e Bases da Educação (LDB 9.394/96) e o Fundo de Manutenção e Desenvolvimento da Educação Básica e de Valorização dos Profissionais da Educação (FUNDEB).

Por ser a Lei 13.415/2017, fruto da MP 746/2016, o principal instrumento a partir do qual o governo se põe a intervir nos desafios do Ensino Médio brasileiro, nos dedicaremos a analisá-la a seguir.

\section{A reforma que deforma: o Novo Ensino Médio e o falso enfrentamento dos velhos desafios da educação brasileira}

Prevista no artigo 62 da Constituição Federal de 1988, a Medida Provisória se constitui em uma lei editada pelo Presidente da República que, apesar de ser submetida à apreciação do Congresso Nacional e poder ser alterada ou rejeitada por este, já passa a vigorar no ato de sua publicação pelo Poder Executivo.

Outra característica importante desse dispositivo jurídico é que ele deve ser usado em casos de relevância e urgência e força o Congresso Nacional a apreciálo dentro de um prazo de apenas 60 dias, na medida em que, mesmo

\footnotetext{
18 Disponível em: Acesso em: http://g1.globo.com/educacao/noticia/governo-exclui-96-dosinstitutos-federais-em-divulgacao-do-enem-porescola.ghtml?utm source=facebook\&utm medium=share-bar-desktop\&utm campaign=share-bar . 05 nov. 2016.

${ }^{19}$ Disponível

em: http://portal.inep.gov.br/c/journal/view article content?groupld=10157\&articleld=169771\&version= 1.1. Acesso em: 22 nov. 2016.
}

TrabalhoNecessario - www.uff.br/trabalhonecessario; Ano 15, № 26/2017 
podendo ser prorrogável por igual período, caso transcorram 45 dias de sua publicação e não seja concluída, a MP tranca a pauta da Casa Legislativa na qual se encontra.

Por aí, podemos ter uma ideia da gravidade da situação: a Lei 13.415/2017 resulta de um dispositivo jurídico-político que procura reformar uma etapa educacional repleta de problemas estruturais e históricos sem debates com a sociedade ${ }^{20}$ e de forma aligeirada no Congresso Nacional. Vamos ao documento.

Embora exista uma diferença na quantidade de artigos entre a versão inicial (Medida Provisória 746/2016) e a versão final (Lei n. 13.415/2017) dos dispositivos legais que instituem a reforma do Ensino Médio, eles podem ser agrupados em três eixos temáticos: 1) Ensino Médio em Tempo Integral; 2) Reestruturação Curricular; 3) Dispensa da licenciatura para atuação como professor na área de conhecimento "formação técnica e profissional".

No aspecto temático, a reforma do autoproclamado Novo Ensino Médio não é inovadora. Em dois dos eixos ela não somente assume, como também torna pior as propostas já debatidas no âmbito do Projeto de Lei nº 6.840, de 2013, fruto de 17 meses de trabalho de uma comissão especial, instituída na Câmara dos Deputados, e incumbida de promover estudos e proposições para a reformulação do Ensino Médio²1. Entre as polêmicas propostas do PL 6.840/2013 que a MP 746/2016 e a Lei 13.415/2017 assumem estão: a adoção do Ensino Médio em tempo integral; a efetivação da organização curricular por áreas de conhecimento (linguagens, matemática, ciências da natureza e ciências humanas); e o direcionamento de parte do Ensino Médio para aprofundamento em uma das áreas de conhecimento ou em uma habilitação profissional' ${ }^{22}$.

O primeiro dos eixos temáticos é a inclusão, no artigo 24 da LDB 9.394/96, de um parágrafo que prevê a progressiva ampliação da carga horária mínima

\footnotetext{
${ }^{20}$ Embora todo o processo de tramitação da MP 746/2016 tenha sido marcado por protestos e resistência de estudantes (inclusive por meio da ocupação de escolas), professores e instituições educacionais de todo o país, a referida proposta de lei chega à sua versão final (Lei $n$. 13.415/2017) sem alterações substanciais ou incorporação das demandas dos manifestantes contrários à MP.

${ }^{21}$ Uma síntese dessas críticas pode ser consultada em texto do Movimento Nacional pelo Ensino Médio, composto por 10 entidades do campo educacional, que resistem à aprovação do PL 6.840/2013. Este e outros textos contrários ao referido projeto podem ser acessados no Portal do Observatório do Ensino Médio, da Universidade Federal do Paraná (UFPR): http://www.observatoriodoensinomedio.ufpr.br/movimento-nacional-em-defesa-do-ensino-medio/. ${ }^{22}$ O PL 6.840/2013 propunha que apenas o terceiro ano de escolaridade tivesse esse direcionamento diferenciado.
}

TrabalhoNecessario - www.uff.br/trabalhonecessario; Ano 15, № 26/2017 
anual do Ensino Médio de 800 horas para 1.400 horas. Com isso, a reforma do Ensino Médio procura incentivar a adoção do Ensino Médio em Tempo Integral, instituindo, no âmbito do Ministério da Educação (MEC), uma política de fomento e transferência de recursos financeiros aos sistemas de ensino que aderirem à proposta.

Vista de forma isolada, a medida parece interessante, pois supostamente assume o desafio de contribuir com a implementação de escolas de Ensino Médio em tempo integral, oferecendo, entre outras possibilidades, maior dedicação aos estudos, ampliação das potencialidades estudantis em áreas como esporte, cultura e lazer e melhor aproveitamento do tempo escolar.

No entanto, dizemos supostamente porque o referido dispositivo legal não dispõe de condições reais para se efetivar, tendo em vista que, para tal, precisaria enfrentar, entre outros, desafios como: forte investimento na infraestrutura das escolas para adaptá-las à nova realidade, adoção de uma política de formação e trabalho docente em tempo integral e com dedicação exclusiva, e concessão de bolsas de estudo para os estudantes de baixa renda que, desde cedo, precisam conciliar escola e trabalho.

Apesar de o Censo Escolar da Educação Básica de 2013 mostrar que é razoável a infraestrutura das escolas de Ensino Médio, na medida em que 87,7\% delas apresentam bibliotecas ou salas de leitura; $93,2 \%$ têm acesso à internet; $91,5 \%$ possuem laboratório de informática e $75,5 \%$ têm quadra esportiva, esses recursos são insuficientes para a demanda de tempo integral, tendo em vista que os estudantes não somente precisariam passar todo o dia nas dependências da escola, como também, necessitariam de espaços e equipamentos para desenvolver atividades esportivas, culturais, cientificas e/ou tecnológicas, que vão além do ambiente e dos recursos hoje oferecidos.

Sobre a atual situação dos docentes e dos estudantes do Ensino Médio, conforme já indicamos na seção anterior, esta não é nada favorável à escolarização em tempo integral sem o seu devido enfrentamento.

A reforma do Ensino Médio (MP 746/2016 e Lei n. 13.415/2017) até se propõe a garantir recursos para atender essas e outras demandas. No entanto, essa promessa, além de difícil, se torna impraticável sob a vigência da Emenda 
Constitucional n. 95, de 15 de dezembro de 2016 23 , a qual instituiu um novo regime fiscal, estabelecendo limites para o aumento das despesas públicas. Isso afeta diretamente direitos sociais como educação e saúde, pois, na prática, a EC 95, ao condicionar, por um período de 20 anos (até 2036), os gastos públicos ao montante investido no ano anterior mais o reajuste da inflação, congela os investimentos sociais e legitima a ideologia do Estado mínimo. Neste cenário, como garantir o repasse de recursos de forma suficiente para atender as demandas dos sistemas de ensino na implementação da escola de tempo integral?

O segundo eixo temático da reforma do Ensino Médio diz respeito à reestruturação curricular do Ensino Médio. De acordo com a Lei 13.415/2017, somente Língua Portuguesa e Matemática são componentes obrigatórios nos três anos do Ensino Médio24, ficando as demais disciplinas condicionadas ao que for estabelecido pela versão final da Base Nacional Comum Curricular (BNCC) ${ }^{25} \mathrm{e}$ obrigatórias somente até o limite da carga horária máxima destinada ao cumprimento da BNCC (1.800 horas $\left.{ }^{26}\right)$.

Essa mudança tem sérias implicações, seja no que tange ao lugar dos componentes curriculares na formação dos estudantes, seja no tocante à fragmentação do caráter formativo e universal do Ensino Médio, defendido pela LDB 9.394/96, ou ainda no que diz respeito à vinculação direta e imediata entre o Ensino Médio e a formação de força de trabalho para o mercado, e o aligeiramento da formação média e superior.

No primeiro caso, o cenário é de insegurança para a maioria dos componentes curriculares, tendo em vista que estes deixam de ser garantidos como obrigatórios por uma lei cuja mudança precisa da apreciação do Congresso Nacional (a LDB), e ficam dependentes de "aprovação do Conselho Nacional de

\footnotetext{
${ }^{23} \mathrm{Na}$ Câmara dos Deputados a referida lei tramitou como PEC 241/2016. Já no Senado, ela foi apreciada sob a denominação PEC 55/2016.

${ }^{24} \mathrm{O}$ ensino de Língua Inglesa também é definido pela MP 746/2016 e pela Lei $13.415 / 2017$ como obrigatório, embora não fique clara a sua duração, como Língua Portuguesa e Matemática.

${ }^{25}$ Documento em elaboração, desde junho de 2015, sob a coordenação da Secretaria de Educação Básica (SEB) do MEC, e voltado à definição dos conhecimentos básicos que os estudantes deverão ter acesso, em cada componente curricular, da Creche ao Ensino Médio. A elaboração do documento envolveu vários segmentos da sociedade brasileira, inclusive, com abertura para proposição via internet.

${ }^{26}$ A MP 746/2016 propunha que o limite para o cumprimento da BNCC fosse de apenas 1.200 horas.
}

TrabalhoNecessario - www.uff.br/trabalhonecessario; Ano 15, № 26/2017 
Educação e de homologação pelo Ministro de Estado da Educação 27" (Brasil, 2017, art. 2º, § 10).

Conhecendo a história de disciplinas marcadas pela intermitência e pela falsa suspeita de doutrinação ideológica de esquerda, como é o caso da Sociologia e da Filosofia, não é exagerado o receio de que estas correm sérios riscos de exclusão, sobretudo, em um cenário no qual, propostas como a do Projeto Escola Sem Partido ${ }^{28}$ recebem adesão de parlamentares e do próprio Ministro de Estado da Educação.

Com relação à fragmentação do caráter formativo e universal do Ensino Médio, isso é ainda mais grave, pois retira do estudante secundarista a possibilidade de ter uma Educação Básica por inteiro, na medida em que reduz a universalidade a no máximo 1.800 horas (pouco mais de 1 ano e meio), tempo insuficiente para desenvolver as habilidades mínimas necessárias para situar-se no mundo como sujeito de sua própria história. Claro que, com isso, não estamos dizendo que o Ensino Médio como "está" cumpra adequadamente esta função. Contudo, tampouco acreditamos que seja a redução do tempo de contato do estudante com o conhecimento historicamente acumulado que irá resolver os problemas que hoje afetam a etapa educacional em tela.

Por outro lado, poder-se-ia argumentar que não haverá fragmentação, na medida em que, após a metade do curso, o estudante teria a possibilidade de prosseguir o Ensino Médio em um dos cinco itinerários formativos indicados, a saber: 1) linguagens e suas tecnologias; 2) matemática e suas tecnologias; 3) ciências da natureza e suas tecnologias; 4) ciências humanas e sociais aplicadas; 5) formação técnica e profissional.

No entanto, isso em nada altera o caráter fragmentário da nova proposta curricular, uma vez que, embora caiba aos sistemas de ensino organizar os seus currículos a partir de uma ou mais área de conhecimento, estes precisarão dispor de condições para concretizarem tal oferta, e os estudantes somente poderão

\footnotetext{
${ }^{27}$ A MP 746/2016 exigia ainda que fossem ouvidos o Conselho Nacional de Secretários de Educação - Consed e a União Nacional de Dirigentes de Educação - Undime.

${ }^{28}$ Trata-se de um movimento criado em 2004, pelo advogado Miguel Nagib, e que, desde 2014, vem protagonizando, nas esferas municipal, estadual e federal, a apresentação de projetos de lei que buscam criminalizar o que denomina "doutrinação ideológica de esquerda" na sala de aula. Os professores Lalo Watanabe Minto, Fabiana Cássia Rodrigues e Anibal Gonzalez, pesquisadores da UNICAMP, organizaram para o blog Marxismo21, um excelente dossiê sobre o assunto, envolvendo artigos, entrevistas, sites, vídeos, manifestos e matérias publicadas na imprensa. Disponível em: http://marxismo21.org/escola-sem-partidol. Acesso em: 09 out. 2016.
}

TrabalhoNecessario - www.uff.br/trabalhonecessario; Ano 15, №26/2017 
cursar um segundo itinerário após a conclusão de outro - e ainda a depender da disponibilidade de vaga na rede. Também destaque-se que a opção pelos itinerários somente eliminaria a fragmentação se o estudante pudesse passar por todos eles, de forma concomitante ou subsequente, o que no primeiro caso (concomitante), dispensaria a existência dos mesmos, e no segundo (subsequente), elevaria a duração do Ensino Médio para cerca de 9 anos de escolaridade.

Além disso, a fragmentação do Ensino Médio também pouco ou nada influi sobre problemas atuais, a exemplo da repetência e do abandono escolar. Comumente atribuídos ao currículo, por ser desinteressante e alheio à realidade juvenil, estes indicadores de rendimento podem piorar sob a nova reconfiguração da etapa educacional em tela, uma vez que os sistemas de ensino oferecerão itinerários formativos limitados e estes nem sempre corresponderão às expectativas dos estudantes, deixando insatisfeitos ou à margem aqueles que preferiam estar cursando outro caminho de estudo.

A terceira consequência da reestruturação curricular é a vinculação direta e imediata entre o Ensino Médio e a formação de força de trabalho para o mercado. Isto é, ao oferecer como um dos itinerários formativos a "formação técnica e profissional" em padrão totalmente diferente daquele proposto aos Institutos Federais de Educação, Ciência e Tecnologia (IFs) ${ }^{29}$, a reforma do Ensino Médio induz os sistemas de ensino a oferecerem força de trabalho o mais rápido possível ao mercado de trabalho, inclusive, abrindo brechas para as parcerias público-privadas e para a contabilização da venda da força de trabalho estudantil como tempo de formação escolar.

Essa medida em nada ajuda a situação do estudante-trabalhador. Pelo contrário, ela legitima a exploração precoce e precariza ainda mais a formação dos estudantes, na medida em que estes agora podem dedicar-se somente à prática profissional sem precisarem compreender minimamente seus elementos histórico-filosóficos, científicos, estéticos e políticos. Também não se pode perder de vista que, neste particular, a reforma do Ensino Médio afronta as Diretrizes

\footnotetext{
${ }^{29} \mathrm{O}$ Ensino Médio Integrado, oferecido pelos IFs, se alicerça na indissociabilidade entre ensino, pesquisa e extensão, bem como, na oferta de uma educação onilateral, sendo o trabalho concebido, não como sinônimo de emprego (venda da força de trabalho), e sim, em sua dimensão ontológica (responsável pela existência e a reprodução do ser social) e histórica. Neste sentido, não se procura, através dos IFs, promover a formação precoce de força de trabalho, como deseja a MP 746/2016, e sim, a formação do ser humano integralmente (Brasil, 2012b; Moura, 2014).
}

TrabalhoNecessario - www.uff.br/trabalhonecessario; Ano 15, № 26/2017 
Curriculares Nacionais para o Ensino Médio (Brasil, 2012a), que estabelece como princípios nucleadores da organização curricular dessa etapa educacional, o trabalho em sua dimensão histórica e ontológica, a ciência, a cultura e a tecnologia. Ou seja, ao reduzir o trabalho à sua dimensão histórica capitalista, enquanto venda da força de trabalho, a reforma do Ensino Médio desmerece o papel deste na constituição e na estruturação da vida social, reduzindo-o à condição de emprego. Já com relação aos demais princípios (ciência, cultura e tecnologia), reforma do Ensino Médio os fragmenta e isola, permitindo o acesso limitado a apenas alguns deles, a depender do itinerário formativo escolhido.

A quarta consequência da reestruturação curricular é o aligeiramento da formação média. Ou seja, ao abrir a possibilidade de que o Ensino Médio possa ser organizado em módulos e adotar o sistema de créditos disciplinares, a reforma do Ensino Médio desconsidera a especificidade e o perfil dos sujeitos que frequentam a última etapa da Educação Básica. Como resultado, podemos esperar a entrega de um produto ao mercado (a força de trabalho) nos padrões fast food.

O terceiro eixo temático da reforma do Ensino Médio é tão ou mais problemático que os dois primeiros. Trata-se de uma mudança que fere de morte o processo de formação, trabalho e carreira docente, na medida em que abre brecha para a contratação de professores sem licenciatura, exigindo-se apenas "notório saber" em áreas relacionadas ao itinerário formativo denominado "formação técnica e profissional". Ora, tal medida desconsidera e segue na contramão da luta histórica e dos debates contemporâneos ${ }^{30}$ que apontam a necessidade urgente de se investir na formação didático-pedagógica, em nível inicial e continuado, dos professores que atuam com a educação profissional e tecnológica no Brasil, tendo em vista as debilidades que comprometem a qualidade dos serviços educacionais prestados pelos docentes sem a devida formação pedagógica.

Assim, ao invés de avançar no tempo, enfrentando os desafios contemporâneos do Ensino Médio, a reforma do Ensino Médio ressuscita o artigo 9o do Decreto n. 2.208, de 17 de abril de 1997, que abria a possibilidade de que o currículo do ensino técnico fosse ministrado não apenas por professores de

${ }^{30}$ Ver a respeito, entre outros, os estudos de Machado (2008) e Moura (2014).

TrabalhoNecessario - www.uff.br/trabalhonecessario; Ano 15, № 26/2017 
formação, mas também por instrutores e monitores, selecionados, principalmente, com base em sua experiência profissional (o atual notório saber). É mais um ataque às condições de formação, trabalho e carreira docente, pois além de por em risco os postos de trabalho, com a desobrigatoriedade e a redução drástica da carga horária da maioria dos componentes curriculares, a reforma do Ensino Médio menospreza a formação didático-pedagógica, dando a entender que qualquer profissional pode ser professor, bastando ser considerado portador de "notório saber".

\section{Considerações finais}

No decorrer do presente texto, buscamos apresentar alguns dos avanços e desafios que caracterizam o Ensino Médio no Brasil, bem como, analisamos os possíveis impactos da Lei n. 13.415, de 16 de fevereiro de 2017, fruto da Medida Provisória n. 746, de 22 de setembro de 2016, na reconfiguração da etapa educativa em discussão.

Ao longo do texto, acreditamos ter demonstrado que, apesar de avanços como: a garantia legal de universalização dessa etapa educacional, sua inserção no FUNDEB, sua reintegração com a Educação Profissional e a aprovação das novas DCNEM, persistem problemas estruturais e históricos como: a oscilação negativa na taxa de matrícula, o baixo desempenho nos exames nacionais, o elevado índice de reprovação e abandono escolar, a falta de políticas de assistência aos estudantes-trabalhadores e as insuficientes condições de formação, trabalho e carreira docente.

Frente a estes desafios, aludimos que propostas de intervenção como aquelas materializadas na Lei n. 13.415/2017, longe de representarem o real enfrentamento dos problemas que assolam a etapa educacional em tela, pioram a situação. Isso porque, na medida em que desconsidera as causas daquilo que busca enfrentar, a referida Lei acaba legitimando a dualidade estrutural, tendo em vista que não somente precariza a formação dos filhos da classe trabalhadora, como também, incentiva-os a se profissionalizarem de forma precoce. Com isso, embora não seja legalmente vetada a possibilidade de prosseguimento dos estudos, na prática, esta se torna mais distante, seja devido as desigualdades de condições que se manifestam nos processos seletivos, seja em face da dura escolha entre o estudo e o trabalho.

TrabalhoNecessario - www.uff.br/trabalhonecessario; Ano 15, № 26/2017 
Já aos filhos da classe dominante, que dispõem não apenas de melhores condições para se dedicarem aos estudos, mas também, frequentam escolas particulares ou públicas capazes de oferecer itinerários formativos em maior quantidade e melhor qualidade, fica garantida a continuidade dos estudos e a ocupação dos postos de comando.

Assim, concluímos defendendo que não há dúvidas acerca da relevância e da urgência de se intervir no Ensino Médio brasileiro. Contudo, consideradas as questões postas ao longo deste estudo, pensamos que a MP 746/2016, convertida na Lei n. 13.415/2017, não promoverá uma reforma do Ensino Médio, e sim, o deformará ainda mais, na medida em que cria as condições adequadas para a separação de fato e de direito entre aqueles que estudam para mandar e aqueles que estudam somente para fazer.

\section{Referências}

ABREU, Jayme. A educação secundária no Brasil: ensaio de identificação de suas características principais. Revista Brasileira de Estudos Pedagógicos, Brasília, v. 86, n.212, p. 39-84, jan./abr. 2005.

BEHRING, Elaine Rosseti; BOSCHETTI, Ivanete. Política social: fundamentos e história. 9. ed. São Paulo: Cortez, 2011.

BRASIL. Lei 1.076, de 31 de março de 1950. Assegura aos estudantes que concluírem curso de primeiro ciclo do ensino comercial, industrial ou agrícola, o direito à matrícula nos cursos clássico e científico e dá outras providências. Diário Oficial da União, Rio de Janeiro, 12 de abril de 1950.

. Lei no 4.024, de 20 de dezembro de 1961. Fixa as diretrizes e bases da educação nacional. Diário Oficial da União, Brasília, 27 de dezembro de 1961.

. Lei $n^{0} 5.692$, de 11 de agosto de 1971. Fixa diretrizes e bases para o ensino de $1^{\circ}$ e $2^{\circ}$ grau e, dá outras providências. Diário Oficial da União, Brasília, 12 de agosto de 1971.

. Lei $\mathrm{n}^{\circ} \mathbf{7 . 0 4 4}$, de 18 de outubro de 1982. Altera dispositivos da Lei $\mathrm{n}^{\circ}$ 5.692, de 11 de agosto de 1971, referentes a profissionalização do ensino de $2^{\circ}$ grau. Diário Oficial da União, Brasília, 19 de outubro de 1981.

. Constituição da República Federativa do Brasil de 1988. Diário Oficial da União, Brasília, 05 de outubro de 1988.

. Lei no 9.394, de 20 de dezembro de 1996. Estabelece as diretrizes e bases da educação nacional. Diário Oficial da União, Brasília, 23 de dezembro de 1996.

TrabalhoNecessario - www.uff.br/trabalhonecessario; Ano 15, № 26/2017 
. Decreto $\mathrm{n}^{\circ}$ 2.208, de 17 de abril de 1997. Regulamenta o $\S 2^{\circ}$ do art. 36 e os arts. 39 a 42 da Lei o 9.394, de 20 de dezembro de 1996, que estabelece as diretrizes e bases da educação nacional. Diário Oficial da União, Brasília, 18 de abril de 1997.

. Parecer CNE/CEB no 16, de 05 de outubro de 1999. Trata das Diretrizes Curriculares Nacionais para a Educação Profissional de Nível Técnico. Disponível em: http://portal.mec.gov.br/cne/arquivos/pdf/1999/pceb016 99.pdf. Acesso em: 10 dez. 2014.

Decreto n. 5.154 de 23 de junho de 2004. Regulamenta o § 2으 do art. 36 e os arts. 39 a 41 da Lei № 9.394, de 20 de dezembro de 1996, que estabelece as diretrizes e bases da educação nacional, e dá outras providências. Diário Oficial da União, Brasília, 26 de julho de 2004.

. Lei no 11.494, de 20 de junho de 2007. Regulamenta o Fundo de Manutenção e Desenvolvimento da Educação Básica e de Valorização dos Profissionais da Educação - FUNDEB. Diário Oficial da União, Brasília, 21 de junho de 2007.

. Lei n. 11.741, de 16 de julho de 2008. Redimensiona, institucionaliza e integra as ações da educação profissional técnica de nível médio, da educação de jovens e adultos e da educação profissional e tecnológica. Diário Oficial da União, Brasília, 17 de julho de 2008a.

. Lei oㅜ 11.738, de 16 de julho de 2008. Institui o piso salarial profissional nacional para os profissionais do magistério público da educação básica. Diário Oficial da União, Brasília, 17 de julho de 2008b.

. Emenda constitucional no 59, de 11 de novembro de 2009. Diário Oficial da União, Brasília, 12 de novembro de 2009.

. Lei n. 12.061, de 27 de outubro de 2009. Altera o inciso II do art. 40 e o inciso VI do art. 10 da Lei ํㅡ 9.394, de 20 de dezembro de 1996, para assegurar o acesso de todos os interessados ao ensino médio público. Diário Oficial da União, Brasília, 28 de outubro de 2009.

Resolução CNE/CEB ํo 2, de 30 de janeiro de 2012. Define diretrizes curriculares nacionais para o ensino médio. Diário Oficial da União, Brasília, 31 de janeiro de 2012a.

Resolução no 6, de 20 de setembro de 2012. Define Diretrizes Curriculares Nacionais para a Educação Profissional Técnica de Nível Médio. Diário Oficial da União, Brasília, 21 de setembro de 2012b.

Projeto de lei no 6.840, de 2013. Altera a Lei o 9.394, de 20 de dezembro de 1996 para instituir a jornada em tempo integral no ensino médio, dispor sobre a organização dos currículos do ensino médio em áreas do conhecimento e dá outras providências. Disponível em: 
http://www.camara.gov.br/proposicoesWeb/prop mostrarintegra?codteor $=120042$ 8\&filename $=P L+6840 / 2013$. Acesso em: 15 set. 2014.

Relatório Educação para Todos no Brasil: 2000-2015. Brasília: MEC, 2014 (versão preliminar).

. Medida Provisória n. 746, de 22 de setembro de 2016a. Institui a Política de Fomento à Implementação de Escolas de Ensino Médio em Tempo Integral, altera a Lei oㅜ 9.394, de 20 de dezembro de 1996 e a Lei o 11.494 de 20 de junho 2007, e dá outras providências. Diário Oficial da União, Brasília, 23 de setembro de 2016.

Resumo técnico: resultado do Índice de Desenvolvimento da Educação Básica 2005-2015. Brasília, INEP, 2016b.

. Lei $\mathrm{n}^{0} 13.415$, de 16 de fevereiro de 2017. Altera as Leis $\mathrm{n}$ os 9.394 , de 20 de dezembro de 1996 dá outras providência. Diário Oficial da União, Brasília, 17 de fevereiro de 2017.

BREMER, Maria Aparecida de Souza; KUENZER, Acácia. Ensino médio integrado: uma história de contradições. Anais do IX Seminário de Pesquisa em Educação da Região Sul - ANPED SUL. 2012. Caxias do Sul - RS: ANPED, 2012.

CONFEDERAÇÃO NACIONAL DOS TRABALHADORES EM EDUCAÇÃO. Atualização do debate da CNTE sobre o piso do magistério público da Educação Básica-PSPN. Brasília: CNTE, 2014.

CURY, Carlos Roberto Jamil. O ensino médio no Brasil: histórico e perspectivas. Educação Em Revista, Belo Horizonte, oㅡ 27, jul. 1998. Disponível em: http://educa.fcc.org.br/pdf/edur/n27/n27a08.pdf. Acesso em: 13 out. 2014.

ENGELS, Friedrich. Sobre o papel do trabalho na transformação do macaco em homem. Ridendo Castigat Mores, 1999.

FERREIRA, Eliza Bartolozzi. Ensino médio no Brasil: os desafios das políticas de garantia do direito a sua universalização. Linhas Críticas, Brasília, DF, v. 17, n. 34, p. 507-525, set./dez. 2011.

FRIGOTTO, Gaudêncio; CIAVATTA, Maria. Perspectivas sociais e políticas da formação de nível médio: avanços e entraves nas suas modalidades. Educação \& Sociedade, [Campinas], v. 32, n. 116, p. 619-638, jul./set. 2011. Disponível em: http://www.scielo.br/pdf/es/v32n116/a02v32n116.pdf. Acesso em: 14 set. 2014.

GOMES, Candido Alberto; et al. Ensino médio: decifra-me ou te devoro. Boletim Técnico do Senac, [Rio de Janeiro], v. 37, n. 1, p. 48-59, jan./abr. 2011. Disponível em: http://www.senac.br/BTS/371/artigo5.pdf. Acesso em: 14 set. 2014. 
INSTITUTO BRASILEIRO DE GEOGRAFIA E ESTATÍSTICA. Síntese de Indicadores Sociais: uma análise das condições de vida da população brasileira. Brasília: IBGE, 2014.

INSTITUTO NACIONAL DE ESTUDOS E PESQUISAS EDUCACIONAIS ANÍSIO TEIXEIRA. Censo Escolar da Educação Básica 2013: resumo técnico. Brasília: INEP, 2014a.

Sistema de Consulta a Matrícula do Censo Escolar - 1997/2014. Brasília: INEP, 2014b. Disponível em: http://portal.inep.gov.br/basica-censo-escolarmatricula. Acesso em 15 jun. 2015.

- Indicadores Educacionais da Educação Básica: média de alunos por turma. Brasília, INEP, 2015. Disponível em: http://portal.inep.gov.br/indicadoreseducacionais. Acesso em: 08 abr. 2017.

KRAWCZYK, Nora Rut. O ensino médio no Brasil. São Paulo: Ação educativa, 2009. (Coleção Em Questão, v. 1).

Novos formatos escolares para novas demandas sociais: o Ensino Médio Integrado. Archivos de Ciencias de la Educación, año 6, oㅡ 6, 4o época, 2012. Disponível em: http://www.archivosdeciencias.fahce.unlp.edu.ar/. Acesso em: 01 out. 2014.

KUENZER, Acacia Zeneida. O ensino médio agora é para a vida: entre o pretendido, o dito e o feito. Educ. Soc., Campinas, ano XXI, oㅜ 70, abr. 2000. Disponível em http://www.scielo.br/pdf/es/v21n70/a03v2170.pdf. Acesso em 14 set. 2014.

A formação de professores para o ensino médio: velhos problemas, novos desafios. Educação \& Sociedade, [Campinas], v. 32, n. 116, p. 667-688, jul./set. 2011. Título do fascículo: O ensino médio e suas modalidades: propostas, problemas e perspectiva. Disponível em: http://www.scielo.br/pdf/es/v32n116/a04v32n116.pdf. Acesso em: 14 set. 2014.

LIBANEO, José Carlos. Pedagogia e pedagogos, para quê? 9. ed. São Paulo: Cortez, 2007.

LÖWY, Michael. Prefácio à edição brasileira. In: MARX, Karl. Crítica do Programa de Gotha. São Paulo: Boitempo, 2012 (seleção, tradução e notas de Rubens Enderle - Coleção Marx-Engels).

MACENO, Talvanes Eugênio. (im)possibilidades e limites da universalização da educação sob o capital. 2005. [s.n]. Dissertação (Mestrado em Educação) Universidade Federal de Alagoas, Maceió, 2005.

MACHADO, Lucília Regina de Souza. Diferenciais inovadores na formação de professores para a educação profissional. Revista Brasileira da Educação Profissional e Tecnológica, Brasília, MEC, SETEC, v. 1, n. 1, jun. 2008. 
MACHADO COSTA, Gilvan Luiz. Configurações, limites e perspectivas do Ensino Médio no Brasil: qualidade e valorização dos professores. Práxis Educativa (Brasil), vol. 8, n.1, p. 85-109, jan.-jun. 2013. Disponível em: http://www.redalyc.org/pdf/894/89427917005.pdf. Acesso em 14 set. 2014.

MANACORDA, Mario Alighiero. História da educação: da Antiguidade aos nossos dias. 3. ed. São Paulo: Cortez, 1992. (tradução de Gaetano Lo Monaco e revisão de Rosa dos Anjos Oliveira e Paolo Nosella).

MARX, Karl. Manuscritos econômico-filosóficos. São Paulo: Boitempo, 2004 (Tradução de Jesus Ranieri).

. Crítica do Programa de Gotha. São Paulo: Boitempo, 2012 (seleção, tradução e notas de Rubens Enderle - Coleção Marx-Engels).

- O capital: crítica da economia política. Livro 1: o processo de produção do capital. São Paulo: Boitempo, 2013 (Tradução de Rubens Enderle).

.; ENGELS, Friedrich. A ideologia alemã. São Paulo: Boitempo, 2007.

. O manifesto do partido comunista. São Paulo: Boitempo, 1998.

MONTAÑO, Carlos. Terceiro setor e questão social: crítica ao padrão emergente de intervenção social. São Paulo: Cortez, 2002.

MOURA, Dante Henrique. Trabalho e formação docente na educação profissional. Curitiba? IFPR-EAD, 2014 (Coleção Formação Pedagógica, v. 3).

PAULO NETTO, José. Desigualdade, pobreza e Serviço Social. Revista Em Pauta, Rio de Janeiro, n. 19, jan.-jun 2007.

.; BRAZ, Marcelo. Economia política: uma introdução crítica. 7. ed. São Paulo: Cortez, 2011.

PEREIRA, Kátia dos Santos. Reformulação do Ensino Médio: nota técnica. Consultoria legislativa, Brasília: Câmara dos Deputados, ago. 2014.

PINTO, José Marcelino de Rezende; AMARAL, Nelson Cardoso; CASTRO, Jorge Abrahão de. $O$ financiamento do ensino médio no Brasil: de uma escola boa para poucos à massificação barata da rede pública. Educ. Soc., Campinas, v. 32, n. 116, p. 639-665, jul.-set. 2011.

SAVIANI, Dermeval. História das ideias pedagógicas no Brasil. 3. ed. rev. Campinas, SP: Autores Associados, 2008 (Coleção memória e educação).

ZIBAS, Dagmar M. L. Refundar o ensino médio? Alguns antecedentes e atuais desdobramentos das políticas dos anos de 1990. Educação e Sociedade, Campinas, v.26, n.92, p.1067-1086, out. 2005.

Recebido em: 13 de setembro de 2016

TrabalhoNecessario - www.uff.br/trabalhonecessario; Ano 15, № 26/2017 
Aprovado em: 02 de maio de 2017 Pubicado em: 4 de junho de 2017 